\title{
The effects of primary thermo-mechanical processing routes and intercritical annealing on the mechanical properties of st37 low carbon steel
}

\author{
M. Alibeyki, H. Mirzadeh*, M. Najafi \\ School of Metallurgy and Materials Engineering, College of Engineering, University of Tehran, \\ P.O. Box 11155-4563, Tehran, Iran
}

Received 31 May 2018, received in revised form 5 July 2018, accepted 24 July 2018

\begin{abstract}
The effect of thermo-mechanical processing routes on the microstructure and mechanical properties of st37 low carbon steel was studied. Several dual phase (DP) ferritic-martensitic steels were produced by intercritical annealing of the martensitic, cold-rolled martensitic, and bimodal-sized ferritic microstructures. The latter microstructure was produced by subcritical tempering of cold-rolled DP steel to develop an aggregate of ultrafine and large ferrite grains. The DP steel obtained by intercritical annealing of cold-rolled martensite was shown to exhibit better strength-ductility balance compared with that obtained by intercritical annealing of the as-quenched martensite due to much finer microstructure and enhancement of work-hardening behavior in the former. The bimodal-sized ferritic structure showed high yield stress, yieldpoint elongation, and less pronounced work-hardening regime. The DP steel obtained by intercritical annealing of bimodal-sized ferritic structure exhibited inferior strength-ductility tradeoff compared with that obtained by intercritical annealing of cold-rolled martensite due to the coarser microstructure in the former. Conclusively, it is possible to enhance the mechanical properties of st37 low carbon steel by simple processing routes.
\end{abstract}

K e y w o r d s: dual phase steels, microstructure, mechanical properties, strain hardening rate

\section{Introduction}

The increasing requirements for passenger safety, vehicle weight, and fuel consumption resulted in the competition between steel and low-density metal industries $[1,2]$. This resulted in the rapid development of higher strength steels known as advanced high strength steels (AHSS), which show high-strength and improved formability and crashworthiness compared with the conventional steel grades [3]. Among different categories of AHSS, the dual phase (DP) steels with the chemical composition similar to conventional steels have received a great deal of attention [4].

Dual phase (DP) steels are typically low carbon steels with a microstructure consisting of martensite phase in the matrix of ferrite. High tensile strength, good ductility, high work hardening rate, continuous yielding behavior, and good weldability are the known advantages of DP steels [5-10]. The ferrite grain size and the amount, morphology, size, composition, and distribution of the martensite islands strongly affect the properties of DP steels [11, 12]. Therefore, many different techniques have been practiced so far to enhance the properties of DP steels; some of them are described below:

(I) The effect of the pre-intercritical microstructure based on heat treatment routes has been demonstrated by Das et al. [13], Ahmad et al. [14], Kalhor and Mirzadeh [15], Cai et al. [16], Seyedrezai et al. [17], and Schemmann et al. [18]. The martensitic microstructure was found to be a better pre-intercritical microstructure compared with the ferritic-pearlitic ones [13-15].

(II) The effect of strain aging and bake hardening on microstructure and mechanical properties of DP steels has been studied by Chang [19], Zuo and Li [20], Ramazani et al. [21], Ormsuptave and Uthaisangsuk [22], Waterschoot et al. [23], Türkmen and Gündüz

*Corresponding author: tel.: +982182084080; fax: +982188006076; e-mail address: hmirzadeh@ut.ac.ir 
[24], and Kuang et al. [25]. The high potentials of this approach have been discussed in these works.

(III) It has been shown that fine-grained DP steels have much better mechanical properties compared to their coarse-grained counterparts. In this regard, development of fine ferrite/carbide aggregate during subcritical annealing of the cold rolled martensite was studied by Azizi-Alizamini et al. [26] and Mirzadeh et al. [12], where the effect of the subsequent intercritical annealing on the development of fine-grained DP steel was discussed. Calcagnotto et al. [27] and Papa Rao et al. [28] used warm deformation and intercritical annealing for grain refinement. The effect of heating rate to the intercritical region on the cold rolled martensite was discussed by Nakada et al. [29]. Intercritical annealing of cold rolled DP microstructures has been considered by Karmakar et al. [30] and Mazaheri et al. [31]. Multiple intercritical annealing for microstructural refinement was taken into account by Ghaemifar and Mirzadeh [32, 33]. The severe plastic deformation techniques [34] and deformation-induced ferrite transformation [35] have also been used for grain refinement.

Despite these excellent works, much more experiments are required to unravel the effect of primary thermo-mechanical processing on mechanical properties of DP steels, especially with the consideration of well-known conventional steels such as st37 low carbon steel. Therefore, the present work aims to deal with this subject.

\section{Experimental materials and procedure}

\subsection{As-received material}

A commercial st37 low carbon steel sheet with the chemical composition (wt.\%) of $0.12 \mathrm{C}-1.11 \mathrm{Mn}-0.16 \mathrm{Si}$ was used in this work. The sheet was received in the as-annealed condition. The $A_{1}$ and $A_{3}$ temperatures were respectively estimated as $\sim 730^{\circ} \mathrm{C}$ and $\sim 897^{\circ} \mathrm{C}$ based on the Trzaska and Park equations as shown in Eq. (1) [36]:

$$
\begin{aligned}
& A_{1}\left({ }^{\circ} \mathrm{C}\right)=739-22.8 \mathrm{C}-6.8 \mathrm{Mn}+18.2 \mathrm{Si}+11.7 \mathrm{Cr}- \\
& -15 \mathrm{Ni}-6.4 \mathrm{Mo}-5 \mathrm{~V}-28 \mathrm{Cu} \text {, } \\
& A_{3}\left({ }^{\circ} \mathrm{C}\right)=955-350 \mathrm{C}-25 \mathrm{Mn}+51 \mathrm{Si}+106 \mathrm{Nb}+100 \mathrm{Ti}+ \\
& +68 \mathrm{Al}-11 \mathrm{Cr}-33 \mathrm{Ni}-16 \mathrm{Cu}+67 \mathrm{Mo} \text {. }
\end{aligned}
$$

\subsection{Processing}

The sheets were austenitized at $1050^{\circ} \mathrm{C}$ followed by water quenching to obtain the martensitic microstructure. Afterwards, three DP steels were processed as schematically shown in Fig. 1:

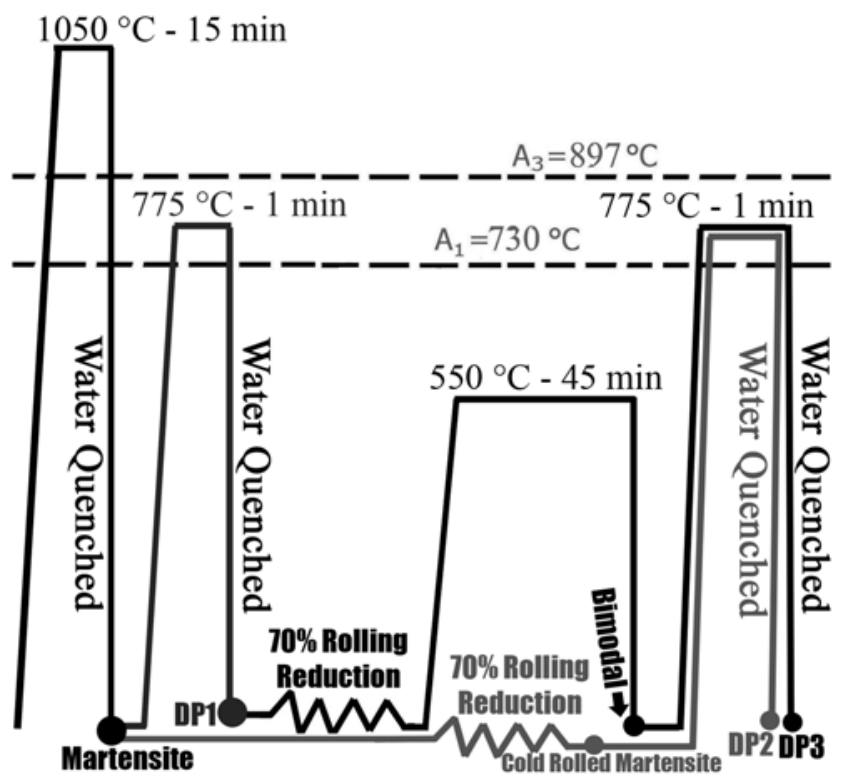

Fig. 1. Schematic representation of the processing routes used in this work.

1. The water quenched specimen was heated to $775^{\circ} \mathrm{C}$ for holding time of $1 \mathrm{~min}$ and then water quenched to produce the dual phase structure with $\sim 20$ vol.\% martensite (DP1).

2. The water quenched specimen was cold rolled with a reduction in thickness of $70 \%$. Afterwards, it was heated to $775^{\circ} \mathrm{C}$ for holding time of $1 \mathrm{~min}$ and then water quenched to produce another dual phase ferritic-martensitic structure (DP2).

3. The DP1 sheet was cold rolled with a reduction in thickness of $70 \%$. Then, it was subjected to tempering at $550{ }^{\circ} \mathrm{C}$ for $45 \mathrm{~min}$ to obtain a steel with bimodal sized ferrite (known as Bimodal steel in this work), where the choice of tempering temperature and time was based on the recent results reported by Najafi et al. [37] for obtaining an ultrafine grained (UFG) ferrite-carbide aggregate from the cold-rolled martensite. Afterwards, the sheet was heated to $775^{\circ} \mathrm{C}$ for holding time of $1 \mathrm{~min}$ and then water quenched to produce another dual phase ferritic-martensitic structure (DP3).

\subsection{Characterization}

Etching in the $2 \%$ Nital solution was used to reveal microstructural features for optical microscopy (Olympus Vanox optical microscope) and scanning electron microscopy (CamScan MV 2300 SEM). The tensile specimen was prepared according to JIS Z 2201 standard. The tensile tests were performed at room temperature using a universal testing machine under a strain rate of $0.001 \mathrm{~s}^{-1}$. The work-hardening rate $(\mathrm{d} \sigma / \mathrm{d} \varepsilon)$ was calculated based on the central 

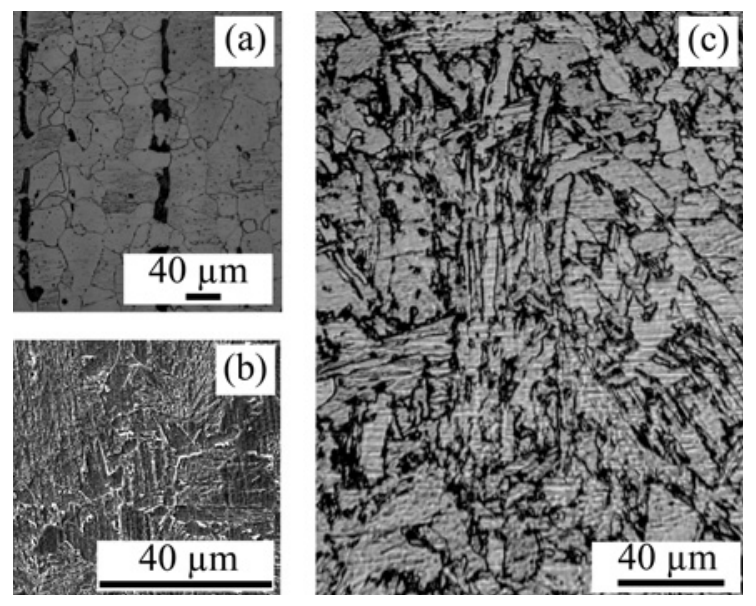

Fig. 2. Representative microstructures of heat treated sheets: (a) As-received, (b) martensite, and (c) DP1. In the DP1 microstructure, the darker phase is martensite.

difference approach [38-40] expressed as $\mathrm{d} \sigma /\left.\mathrm{d} \varepsilon\right|_{\mathrm{i}}=$ $\left\{\sigma_{i+1}-\sigma_{i-1}\right\} /\left\{\varepsilon_{i+1}-\varepsilon_{i-1}\right\}$. The modified CrussardJaoul analysis $[41,42]$ was used, which is based on the Swift formula expressed as $\varepsilon=A+B \sigma^{p}$, where $A, B$, and $p$ are constants. Therefore, $\sigma=\sqrt{[p]}(\varepsilon-A) / B$, then $\mathrm{d} \sigma / \mathrm{d} \varepsilon=\sigma /(p(\varepsilon-A))$, and finally $\ln (\mathrm{d} \sigma / \mathrm{d} \varepsilon)=$ $(1-p) \ln \sigma-\ln (p B)$. As a result, double-logarithmic plots of $\mathrm{d} \sigma / \mathrm{d} \varepsilon$ vs. $\sigma$ can be used to analyze the workhardening behavior.

\section{Results and discussion}

\subsection{The effect of intercritical heat treatment (DP1)}

Representative microstructures of the as-received, martensitic, and DP1 sheets are shown in Fig. 2. The as-received microstructure consists of ferrite grains with an average grain size of $\sim 35 \mu \mathrm{m}$ and pearlite with the banded morphology (Fig. 2a). The presence of the banded structure can be related to the inhomogeneity in the chemical composition of austenite, which originates from the micro-segregation during solidification. Elements like Mn segregate to the regions between delta-ferrite dendrite arms, forming regions with low $A_{3}$ temperatures. Subsequent rolling processes result in the elongation of both regions. During cooling to room temperature, ferrite first forms in the pancaked regions with high $A_{3}$ temperatures, and then, pearlite forms in the regions with low $A_{3}$ temperatures. In this way, alternative ferrite/pearlite bands appear in the microstructure [43-47].

The as-quenched sample (Fig. 2b), however, has a typical morphology of lath martensite characterized by pockets, blocks, and laths [48]. During intercritical annealing, the austenite phase nucleates on the abun-

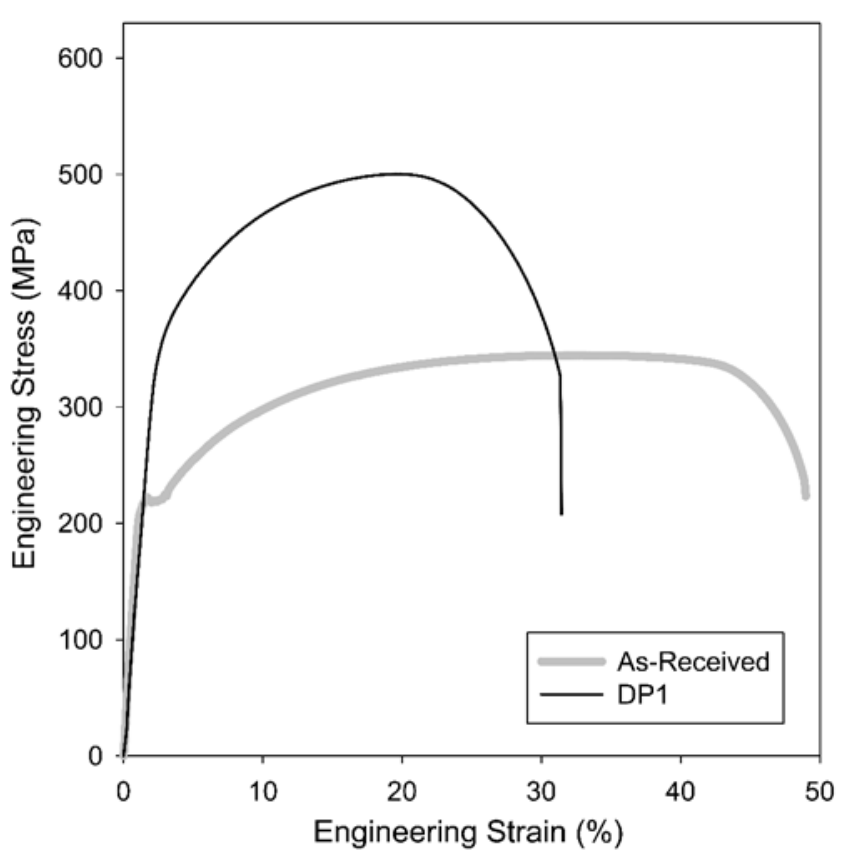

Fig. 3. Tensile stress-strain curves of as-received and DP1 sheets.

dant nucleation sites provided by the martensitic lath microstructure. After water quenching, as shown in Fig. 2c, austenite transforms to martensite and decorates the features of the original lath martensitic microstructure.

Tensile stress-strain curves of the as-received and DP1 sheets are shown in Fig. 3. The yield point phenomenon for the as-received sheet with ferriticpearlitic microstructure can be easily seen, in which after the upper yield point, dislocations are released from the Cottrell atmospheres and the stress drops to the lower yield point, and local plastic deformation spreads grain to grain, producing the yield-point elongation [49]. After that, the normal work hardening regime resumes. After producing dual phase steel (DP1), the yield point phenomenon vanishes due to the presence of free dislocations in ferrite around the martensite particles [50]. The slope of the stress-strain curve for dual phase steel is much higher than that of the as-received sheet. As a result, the dual phase steel shows high strength with maintaining high ductility.

\subsection{Intercritical annealing of the cold rolled sheet (DPQ)}

The DP2 steel was produced by intercritical annealing of the cold-rolled martensite as shown in Fig. 1. Its tensile stress-strain curve is shown in Fig. 4a, where it can be seen that the mechanical properties of DP2 steel are much better than those for DP1 steel. The tensile strength of DP1 is $\sim 500 \mathrm{MPa}$ while that of DP2 is $\sim 600 \mathrm{MPa}$. The total elongation 


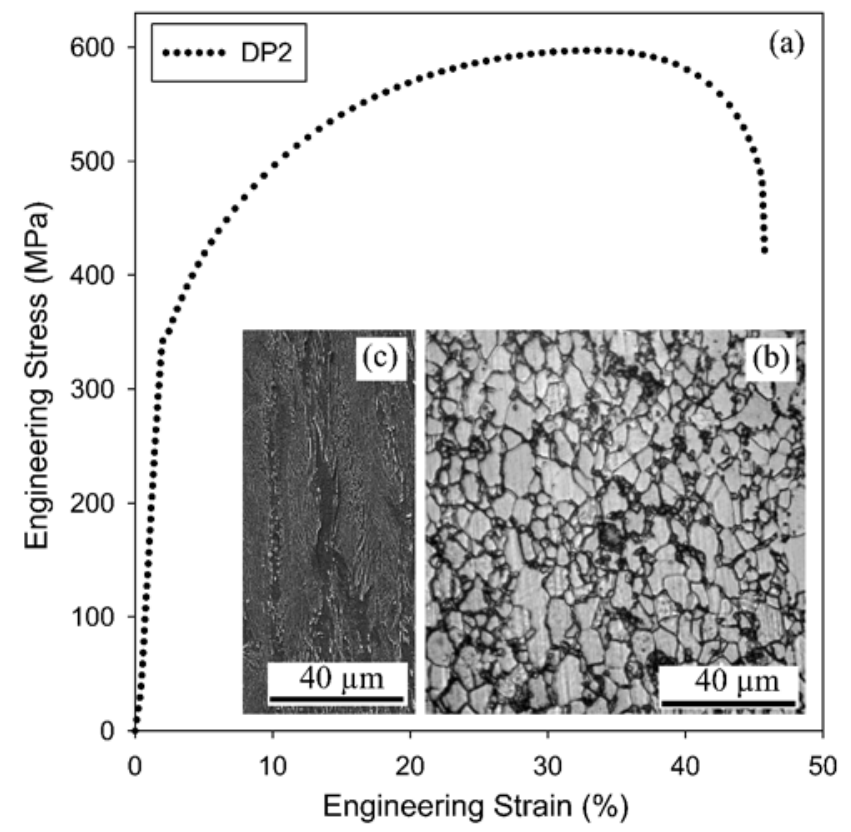

Fig. 4. The tensile stress-strain curve of the DP2 sheet (a), the microstructure of the DP2 sheet (b), and the microstructure of cold rolled martensite (c). In the DP2 microstructure, the darker phase is martensite.

of DP1 is $\sim 30 \%$, but that of DP2 is $\sim 44 \%$. These huge enhancements can be related to the much finer microstructure with better distribution of fine martensite particles as shown in Fig. 4b. It has been shown in several recent works that fine-grained DP steels have an exceptional combination of strength and ductility $[12,26-35,51]$. The ferrite grain size of DP1 and DP2 can be estimated as $\sim 8.28$ and $\sim 4.85 \mu \mathrm{m}$.

The formation of fine-grained DP2 steel is directly related to the initial microstructure before intercritical annealing, i.e., cold-rolled martensitic microstructure. Figure 4c shows the SEM image of the cold-rolled martensite, where a lamellar structure along rolling direction $(\mathrm{RD})$ as a result of the deformation of the lath martensite can be seen (please compare with Fig. 2b). This microstructure provides the requirements for the formation of fine ferrite-austenite microstructure during intercritical annealing, where austenite transforms to martensite during quenching. The result is the formation of fine DP microstructure as shown in Fig. 4b, where the signs of the initial martensitic microstructure cannot be seen due to the occurrence of recrystallization [29].

One of the main advantages of DP steels is the high work hardening rate during straining, which is the basis for their excellent strength-ductility balance [12]. To investigate this property, the work-hardening curves of the as-received, DP1 and DP2 sheets based on the modified Crussard-Jaoul analysis are shown in Fig. 5. Based on Fig. 5, it can be seen that the as-received sheet shows the low work-hardening rate

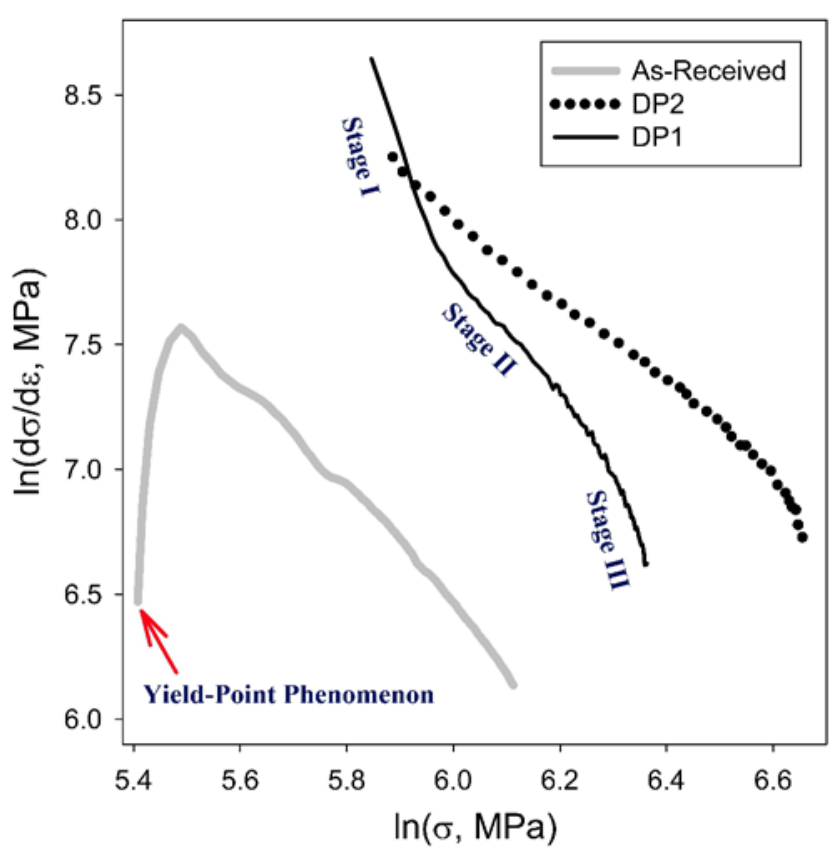

Fig. 5. The work-hardening rate plots based on the modified Crussard-Jaoul analysis for the as-received, DP1, and DP2 sheets.

at the start of plastic deformation, which is related to the occurrence of the yield-point phenomenon. For the DP steels, the initial work-hardening rate is much higher as discussed above. Moreover, three stages of work-hardening can be detected: The transient Stage I represents the glide of mobile dislocations in ferrite present near the martensite regions, Stage II belongs to the deformation of constrained ferrite, and Stage III is related to the concurrent deformation of martensite and hardened ferrite $[13,41,51,52]$. For a major part of the curves, it can be seen that the workhardening curve corresponding to DP2 locates above DP1 at each given flow stress, which reveals that the work-hardening response of DP2 is better.

\subsection{Bimodal-sized ferrite structure (Bimodal)}

As shown in Fig. 1, the cold rolled DP1 sheet was subjected to tempering at $550{ }^{\circ} \mathrm{C}$ for $45 \mathrm{~min}$ to produce the Bimodal steel. The microstructure of this steel (Fig. 6) consists of fine ferrite grains of $\sim 0.9 \mu \mathrm{m}$ originated from the martensitic regions of DP1 steel, and large fine ferrite grains of $\sim 8 \mu \mathrm{m}$ originated from the ferritic regions of DP1 steel. The development of fine ferritic structure in the cold-rolled martensitic microstructure has been recently studied by the present authors [37], and a form of continuous recrystallization was found to be responsible for microstructural changes [37].

The corresponding tensile curve is also shown in Fig. 6, which has high yield stress and tensile strength, 


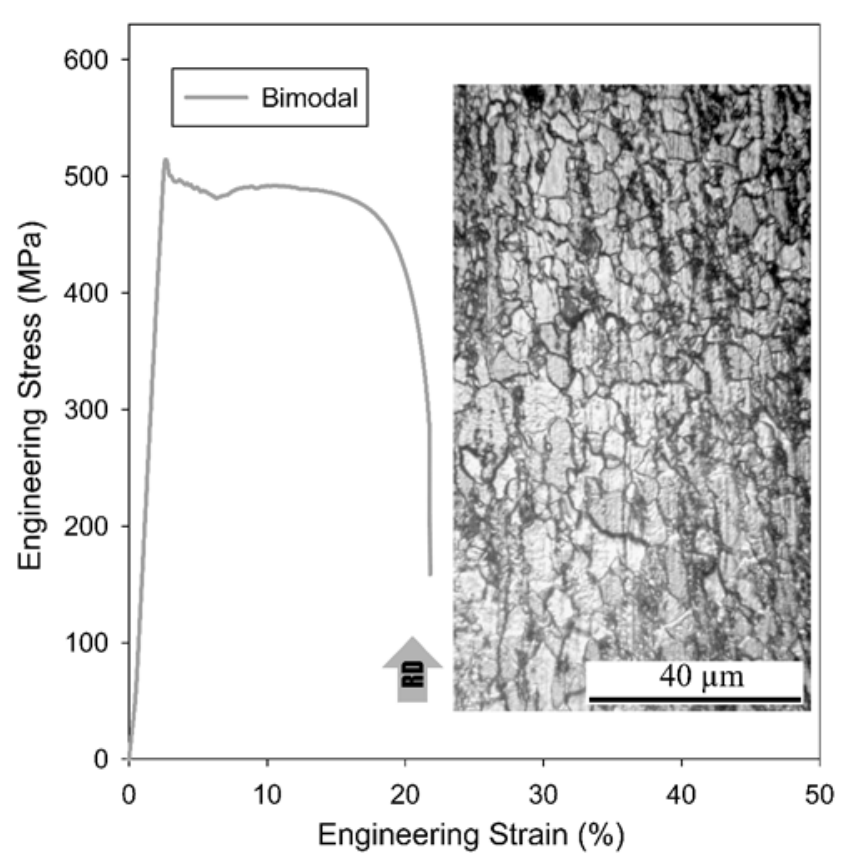

Fig. 6. Tensile stress-strain curve and the microstructure of the Bimodal sheet. In the microstructure, the darker areas contain very fine ferrite grains.

shows yield-point elongation and exhibits lower total elongation. The yield stress of this steel is much higher than other studied sheets in this work, where its yield stress is more than twice that of the asreceived sheet. The presence of fine ferrite grains along with cold-rolled coarse grains resulted in these observations. The lower ductility of this sheet can be explained as follows: When the yield strength of the material increases, e.g., by grain refinement, the flow stress meets the strain-hardening rate at smaller plastic strain (Considére criterion) $[12,53]$. Therefore, limited uniform elongation (and total elongation) is characteristic to UFG microstructures. It can be seen that the tensile strength of this steel is around its yield stress, but it does not break right after yielding and shows some ductility. This is related to the presence of larger ferrite grains. The presence of the bimodal ferrite grain size results in this unique combination of properties [54]. The reappearance of the yield-point phenomenon can be related to the disappearance of the martensitic islands, the annihilation of free dis-

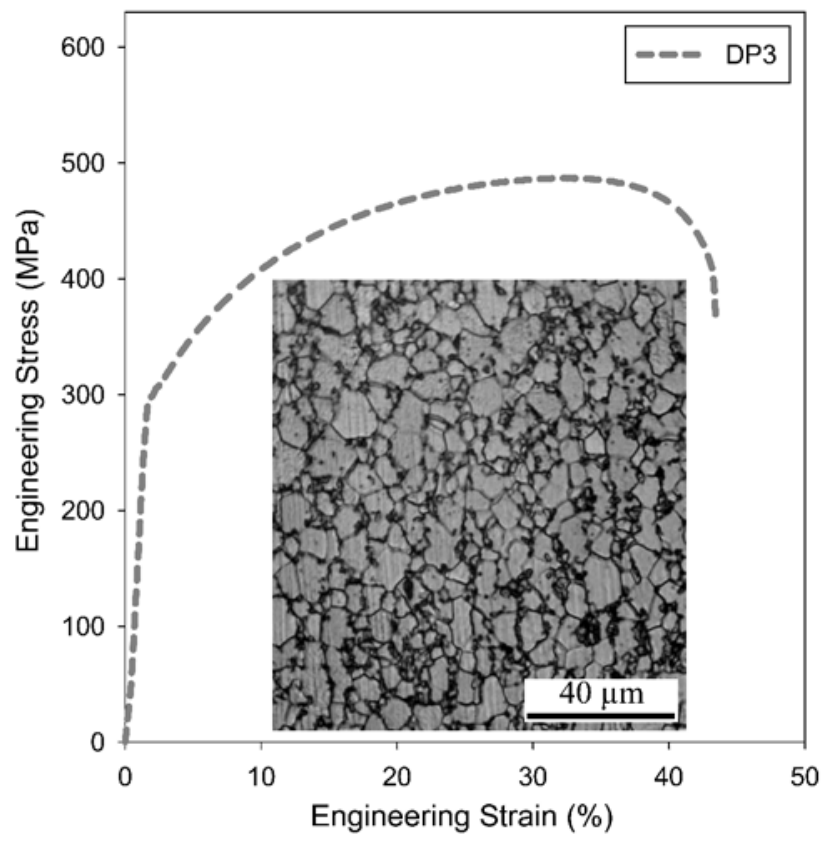

Fig. 7. Tensile stress-strain curve and the microstructure of the DP3 sheet. In the microstructure, the darker phase is martensite.

locations in ferrite, and recreation of Cottrell atmospheres of interstitials around dislocations during subcritical annealing.

\subsection{Intercritical annealing of the Bimodal sheet (DP3)}

The Bimodal steel was heated to $775^{\circ} \mathrm{C}$ for holding time of $1 \mathrm{~min}$, and then water quenched to produce the DP3 steel. The resultant microstructure and mechanical properties are shown in Fig. 7. It can be seen that its tensile strength is comparable to that of DP1 steel (Fig. 3) but with significantly higher total elongation of $\sim 42 \%$ (compared with $\sim 30 \%$ for DP1). Its total elongation is comparable to that of DP2 steel (Fig. 4), but the tensile strength of DP2 steel is more than $100 \mathrm{MPa}$ higher. These results are summarized in Table 1, and these findings can be explained based on the microstructure of DP3 steel, where the ferrite grain size of $\sim 5.20 \mu \mathrm{m}$ was achieved by intercritical annealing of Bimodal steel. This value for the average

Table 1. Summary of microstructural observations and tensile properties of the processed DP steels

\begin{tabular}{cccccc}
\hline Steel & $\begin{array}{c}\text { Martensite } \\
(\text { vol.\%) }\end{array}$ & $\begin{array}{c}\text { Average ferrite grain size } \\
(\mu \mathrm{m})\end{array}$ & $\begin{array}{c}\text { Yield stress } \\
(\mathrm{MPa})\end{array}$ & $\begin{array}{c}\text { Tensile strength } \\
(\mathrm{MPa})\end{array}$ & $\begin{array}{c}\text { Total elongation } \\
(\%)\end{array}$ \\
\hline DP1 & $\sim 20$ & 8.2 & 328.9 & 500.2 & 30 \\
DP2 & $\sim 20$ & 4.8 & 334.7 & 597.2 & 44 \\
DP3 & $\sim 20$ & 5.2 & 292.6 & 486.6 & 42 \\
\hline
\end{tabular}


grain size is between those found for the DP2 and DP1 steels.

Therefore, it can be deduced that the pre-intercritical microstructure is of great importance in the enhancement of the microstructure and mechanical properties of DP steel. In this regard, the cold-rolled martensitic structure is better than the bimodal-sized structure, and the latter is more appropriate compared with the as-quenched martensitic structure.

\section{Conclusions}

The effect of thermo-mechanical processing routes on the microstructure and mechanical properties of st37 low carbon steel was studied. Several dual phase (DP) ferritic-martensitic steels were produced by intercritical annealing of the martensitic, cold-rolled martensitic, and bimodal-sized ferritic microstructures. The following conclusions can be drawn from this work:

1. The as-received ferritic-pearlitic sheet with banded morphology exhibited low strength and high total elongation with the appearance of the yield point phenomenon. However, the DP microstructures showed a good combination of tensile strength and ductility along with much better work hardening response.

2. The bimodal-sized ferritic microstructure can be produced by subcritical tempering of cold-rolled DP steel to develop an aggregate of ultrafine and large ferrite grains. In the present work, fine ferrite grains with an average size of $\sim 0.9 \mu \mathrm{m}$ formed in the martensitic regions of DP steel and large ferrite grains of $\sim 8 \mu \mathrm{m}$ resulted from the cold-rolled ferritic regions. The bimodal-sized ferritic structure showed high yield stress, yield-point elongation, and less pronounced work-hardening regime. The yield stress of this steel is much higher those of other studied sheets in this work, where its yield stress is more than twice that of the as-received sheet.

3 . The DP steel obtained by intercritical annealing of cold-rolled martensite was shown to exhibit better strength-ductility balance compared with that obtained by intercritical annealing of as-quenched martensite due to much finer microstructure and enhancement of work-hardening behavior in the former. The DP steel obtained by intercritical annealing of bimodal-sized ferritic structure exhibited inferior strength-ductility tradeoff compared with that obtained by intercritical annealing of cold-rolled martensite due to its coarser microstructure.

\section{References}

[1] Kuziak, R., Kawalla, R., Waengler, S.: Archives of
Civil and Mechanical Engineering, 8, 2008, p. 103. doi:10.1016/S1644-9665(12)60197-6

[2] Bleck, W., Papaefthymiou, S., Frehn, A.: Steel Research International, 75, 2004, p. 704. doi:10.1002/srin.200405831

[3] Bouaziz, O., Zurob, H., Huang, M.: Steel Research International, 84, 2013, p. 937. doi:10.1002/srin.201200288

[4] Thomser, C., Uthaisangsuk, V., Bleck, W.: Steel Research International, 80, 2009, p. 582. doi:10.2374/SRI09SP046

[5] Tasan, C. C., Diehl, M., Yan, D., Bechtold, M., Roters, F., Schemmann, L., Zheng, C., Peranio, N., Ponge, D., Koyama, M., Tsuzaki, K., Raabe, D.: Annual Review of Materials Research, 45, 2015, p. 19.1. doi:10.1146/annurev-matsci-070214-021103

[6] Kuang, C., Zhang, S., Li, J., Wang, J., Liu, H.: International Journal of Minerals, Metallurgy and Materials, 21, 2014, p. 766. doi:10.1007/s12613-014-0969-7

[7] Kuang, C., Zheng, Z., Wang, M., Xu, Q., Zhang, S.: International Journal of Minerals, Metallurgy and Materials, 24, 2017, p. 1379. doi:10.1007/s12613-017-1530-2

[8] Zhou, L., Zhang, D., Liu, Y.: International Journal of Minerals, Metallurgy and Materials, 21, 2014, p. 755. doi:10.1007/s12613-014-0968-8

[9] Li, P., Li, J., Meng, Q., Hu, W., Kuang, C.: International Journal of Minerals, Metallurgy and Materials, 22, 2015, p. 933. doi:10.1007/s12613-015-1152-5

[10] Mukherjee, M., Tiwari, S., Bhattacharya, B.: International Journal of Minerals, Metallurgy and Materials, 25, 2018, p. 199. doi:10.1007/s12613-018-1563-1

[11] Mazinani, M., Poole, W. J.: Metallurgical and Materials Transactions A, 38,2007 , p. 328 . doi:10.1007/s11661-006-9023-3

[12] Mirzadeh, H., Alibeyki, M., Najafi, M.: Metallurgical and Materials Transactions A, 48, 2017, p. 4565. doi:10.1007/s11661-017-4246-z

[13] Das, D., Chattopadhyay, P. P.: Journal of Materials Science, 44, 2009, p. 2957. doi:10.1007/s10853-009-3392-0

[14] Ahmad, E., Manzoor, T., Ziai, M. M. A., Hussain, N.: Journal of Materials Engineering and Performance, 21, 2012, p. 382. doi:10.1007/s11665-011-9934-z

[15] Kalhor, A., Mirzadeh, H.: Steel Research International, 88, 2017, p. 1600385 . doi:10.1002/srin.201600385

[16] Cai, X. L., Garratt-Reed, A. J., Owen, W. S.: Metallurgical Transactions A, 16, 1985, p. 543. doi:10.1007/BF02814228

[17] Seyedrezai, H., Pilkey, A. K., Boyd, J. D.: Materials Science and Engineering A, 594, 2014, p. 178. doi:10.1016/j.msea.2013.11.034

[18] Schemmann, L., Zaefferer, S., Raabe, D., Friedel, F., Mattissen, D.: Acta Materialia, 95, 2015, p. 386. doi:10.1016/j.actamat.2015.05.005

[19] Chang, P. H.: Metallurgical Transactions A, 15, 1984, p. 73. doi:10.1007/BF02644389

[20] Zuo, X., Li, R.: Steel Research International, 86, 2015, p. 163. doi:10.1002/srin.201300465

[21] Ramazani, A., Bruehl, S., Abbasi, M., Bleck, W., Prahl, U.: Steel Research International, 87, 2016, p. 1559. doi: $10.1002 / \operatorname{srin} .201600060$ 
[22] Ormsuptave, N., Uthaisangsuk, V.: Steel Research International, 88, 2017, p. 1600150. doi:10.1002/srin.201600150

[23] Waterschoot, T., De, A. K., Vandeputte, S., De Cooman, B. C.: Metallurgical and Materials Transactions A, 34, 2003, p. 781. doi:10.1007/s11661-003-0113-1

[24] Türkmen, M., Gündüz, S.: Acta Metallurgica Sinica (English Letters), 27, 2014, p. 279. doi:10.1007/s40195-014-0043-5

[25] Kuang, C., Zhang, S., Li, J., Wang, J., Liu, H.: International Journal of Minerals, Metallurgy and Materials, 21, 2014, p. 766. doi:10.1007/s12613-014-0969-7

[26] Azizi-Alizamini, H., Militzer, M., Poole, W. J.: ISIJ International, 51, 2011, p. 958. doi:10.2355/isijinternational.51.958

[27] Calcagnotto, M., Ponge, D., Raabe, D.: Materials Science and Engineering A, 527, 2010, p. 7832. doi:10.1016/j.msea.2010.08.062

[28] Papa Rao, M., Subramanya Sarma, V., Sankaran, S.: Metallurgical and Materials Transactions A, 45, 2014, p. 5313. doi:10.1007/s11661-014-2478-8

[29] Nakada, N., Arakawa, Y., Park, K. S., Tsuchiyama, T., Takaki, S.: Materials Science and Engineering A, 553, 2012, p. 128. doi:10.1016/j.msea.2012.06.001

[30] Karmakar, A., Mandal, M., Mandal, A., Basiruddin Sk, Md., Mukherjee, S., Chakrabarti, D.: Metallurgical and Materials Transactions A, 47, 2016, p. 268. doi:10.1007/s11661-015-3248-y

[31] Mazaheri, Y., Kermanpur, A., Najafizadeh, A.: ISIJ International, 55, 2015, p. 218. doi:10.2355/isijinternational.55.218

[32] Ghaemifar, S., Mirzadeh, H.: Canadian Metallurgical Quarterly, 56, 2017, p. 459. doi:10.1080/00084433.2017.1361223

[33] Ghaemifar, S., Mirzadeh, H.: Steel Research International, 89, 2018, p. 1700531. doi:10.1002/srin.201700531

[34] Shin, D. H., Park, K. T.: Materials Science and Engineering A, 410-411, 2005, p. 299. doi:10.1016/j.msea.2005.08.025

[35] Mukherjee, K., Hazra, S. S., Militzer, M.: Metallurgical and Materials Transactions A, 40, 2009, p. 2145. doi:10.1007/s11661-009-9899-9

[36] Gorni, A. A.: Steel Forming and Heat Treating Handbook. 2012. www.gorni.eng.br

[37] Najafi, M., Mirzadeh, H., Alibeyki, M: Materials Science and Engineering A, 670, 2016, p. 252. doi:10.1016/j.msea.2016.06.024
[38] Najafi, M., Mirzadeh, H., Alibeyki, M.: Iranian Journal of Materials Forming, 5, 2018, p. 19. doi:10.22099/ijmf.2017.26349.1089

[39] Saadatkia, S., Mirzadeh, H., Cabrera, J. M.: Materials Science and Engineering A, 636, 2015, p. 196. doi:10.1016/j.msea.2015.03.104

[40] Mirzadeh, H., Cabrera, J. M., Prado, J. M., Najafizadeh, A.: Materials Science and Engineering A, 528, 2011, p. 3876. doi:10.1016/i.msea.2011.01.098

[41] Bag, A., Ray, K. K., Dwarakadasa, E. S.: Metallurgical and Materials Transactions A, 30, 1999, p. 1193. doi:10.1007/s11661-999-0269-4

[42] Alibeyki, M., Mirzadeh, H., Najafi, M., Kalhor, A.: Journal of Materials Engineering and Performance, 26, 2017, p. 2683. doi:10.1007/s11665-017-2687-6

[43] Thompson, S. W., Howell, P. R.: Materials Science and Technology, 8, 1992, p. 77. doi:10.1179/mst.1992.8.9.777

[44] Krebs, B., Germain, L., Hazotte, A., Goune, M.: Journal of Materials Science, 46, 2011, p. 7026. doi:10.1007/s10853-011-5671-9

[45] Deldar, S., Mirzadeh, H., Parsa, M. H.: Engineering Failure Analysis, 68, 2016, p. 132. doi:10.1016/j.engfailanal.2016.06.001

[46] Azizi, G., Mirzadeh, H., Parsa, M. H.: Materials Science and Engineering A, 639, 2015, p. 402. doi:10.1016/j.msea.2015.05.045

[47] Azizi, G., Mirzadeh, H., Parsa, M. H.: Steel Research International, 87, 2016, p. 820. doi:10.1002/srin.201500246

[48] Tsuji, N.: Advanced Engineering Materials, 12, 2010, p. 701. doi:10.1002/adem.201000018

[49] Dieter, G. E.: Mechanical Metallurgy. 3rd Edition. New York, McGraw-Hill 1988.

[50] Krauss, G.: Steels Processing, Structure, and Performance. 2nd Edition. Materials Park, ASM International 2015.

[51] Alibeyki, M., Mirzadeh, H., Najafi, M.: Vacuum, 155, 2018, p. 147. doi:10.1016/j.vacuum.2018.06.003

[52] Maleki, M., Mirzadeh, H., Zamani, M.: Steel Research International, 89, 2018, p. 1700412. doi:10.1002/srin.201700412

[53] Zehetbauer, M. J., Zhu, Y. T.: Bulk Nanostructured Materials. Hoboken, Wiley 2009.

[54] Wang, Y., Chen, M., Zhou, F., Ma, E.: Nature, 2002, 419, p. 912. doi:10.1038/nature01133 